\title{
Landscape-scale effects of supra-seasonal drought on semi-aquatic snake assemblages
}

Philip N. Vogrinc ${ }^{\mathrm{a}}$, Andrew M. Durso ${ }^{\mathrm{b}}$, Christopher T. Winne ${ }^{\mathrm{c}}$, and John D. Willson ${ }^{\mathrm{a} *}$

aDepartment of Biological Sciences, University of Arkansas, Fayetteville, AR 72701, USA (pnvogrin@email.uark.edu)

bDepartment of Biology, Utah State University, Logan, UT 84322, USA (amdurso@ gmail.com) 'Savannah River Ecology Laboratory, Aiken, SC 29802, USA (ctwinne@ gmail.com)

*Corresponding Author: Department of Biological Sciences, University of Arkansas, Fayetteville, AR 72701, USA; jwillson@ uark.edu; phone: 479-575-2647; fax: 479-575-4010 


\section{Abstract}

2 Climate change is predicted to alter the frequency and intensity of precipitation events, placing 3 stress on freshwater aquatic ecosystems and their associated wildlife. Thus, understanding 4 interspecific variation in drought sensitivity and the repeatability of those responses across 5 heterogeneous landscapes is critical. Semi-aquatic snakes serve important roles within aquatic

6 ecosystems and several species are threatened. Yet, little is known about the effects of drought

7 on semi-aquatic snake populations or assemblages. We systematically trapped 20 isolated

8 wetlands in South Carolina before (2006) and after (2013) a multi-year supra-seasonal drought to

9 determine drought-induced shifts in occupancy and detection for five semi-aquatic snake species.

10 Our results confirm that supra-seasonal drought differentially affects semi-aquatic snake species

11 across landscape scales. Specifically, site occupancy decreased dramatically following drought

12 for banded watersnakes (Nerodia fasciata) (0.95 to 0.69) and Florida green watersnakes

13 (Nerodia floridana) (0.32 to 0.05), but was relatively unchanged for black swamp snakes

14 (Seminatrix pygaea), mudsnakes (Farancia abacura) and glossy crayfish snakes (Regina rigida).

15 Species lacking adaptations that make them resistant or resilient to drought may become locally 16 extirpated if climate change projections are realized or landscapes are degraded or fragmented in 17 ways that prevent drought recovery.

\section{Keywords}

19 Climate change, communities, environmental stochasticity, occupancy modeling, stochasticity, 20 wetlands

\section{Introduction}

Anthropogenic impacts to climate contribute to rapid environmental changes that have altered ecosystems and eliminated species across the globe (Allen et al. 2010). At least one

24 vertebrate extinction is attributed to climate change (Pounds et al. 1999), and the most 25 conservative climate warming scenarios estimate that approximately $18 \%$ of species are committed to extinction by 2050 (Thomas et al. 2004). One undesirable consequence of global

27 climate change is increased frequency of supra-seasonal drought. Multiple lines of evidence 28 suggest that drought frequency, intensity, and duration will increase in the future in many regions 29 (Dai 2011; Seneviratne et al. 2012; Ficklin et al. 2015). Defined as long, irregular, and 
unpredictable periods of below average rainfall (Lake 2003), supra-seasonal drought can strongly

31 influence the magnitude of other stochastic disturbance events. Prolonged drought desiccates

32 dead and decaying organic materials, increasing their flammability and fire risk (Knight 1987;

33 Bigler et al. 2005). Drought can also reduce the available water, food, and habitat resources

34 within an ecosystem, thereby influencing survival, growth, and reproduction of wildlife. For example, brush-tailed phascogales (Phascogale tapoatafa) suffered 15-25\% reductions in body size and a one-third reduction in species detection probability during drought (Rhind and Bradley 2002). Meta-population dynamics can also be altered, as drought influences movement behavior, which, in turn, can alter rates of dispersal and colonization (Walls et al. 2013a). Finally, as the available surface water across a landscape is limited, wildlife is forced to concentrate, increasing the severity of competition and probability of predation and disease transmission (Kock 2005).

Drought inflicts considerable stress on a variety of organisms, especially those that are closely tied to aquatic systems. Species regularly confronted with drought possess traits that allow them to either persist through drought (resistance) or recolonize and repopulate after drought-induced declines (resilience) (Lake 2000). However, projected increases in drought 45 intensity may be too extreme for even "drought-tolerant" species to withstand (Bond et al. 2008). 46 Population-level impacts of drought have been documented for some taxa, such as fishes (e.g., 47 Larimore et al. 1959; Trape 2009), invertebrates (e.g., Hynes 1958; Harrison 2000), amphibians 48 (Walls et al. 2013b), and birds (e.g., Cahill et al. 2013). Among snakes, sea krait (Laticauda spp.) abundance correlates with precipitation during drought (Lillywhite and Tu 2011) and drought reduced prey abundance, body condition, and survival of ratsnakes (Pantherophis 51 obsoletus) in Texas (Sperry and Weatherhead 2008). Of the organisms vulnerable to climatic 52 changes in aquatic environments, semi-aquatic snakes fall into a peculiar category in regards to 53 their ability to confront change. Semi-aquatic snakes that rely on aquatic habitats for shelter and 54 food can withstand long periods of starvation due to low metabolic demands (Pough 1980), but 55 exhibit limited vagility due to physiological characteristics such as high rates of evaporative 56 water loss and small body size (Winne et al. 2001; Winne et al. 2006). However, due to their low 57 detectability, little is known about the responses of snake populations and assemblages to supra58 seasonal drought events. 
More than two decades of previous herpetological research at Ellenton Bay, a 10 ha

60

61

62 isolated semi-permanent wetland in the Coastal Plain of the southeastern United States, has yielded insight into the influence of drought on semi-aquatic snake population and community dynamics. Since 1974, Ellenton Bay has experienced multiple periodic droughts including three multi-year supra-seasonal droughts (Fig. 1). We found that, at this wetland, highly aquatic black swamp snakes (Seminatrix pygaea) were least impacted by drought, exhibiting resistance by aestivating within the wetland and exhibiting little change in relative abundance over multi-year droughts (Willson et al. 2006; Winne et al. 2006). Conversely, banded watersnake (Nerodia fasciata) populations severely declined, but exhibited resilience by quickly recovering through rapid reproduction and recruitment when the drought ended (Willson et al. 2006). Exhibiting neither resistance nor resilience, Florida green watersnakes (Nerodia floridana) became locally extirpated, were not detected for three years post-drought, and never regained their pre-drought relative abundance (Seigel et al. 1995; Willson et al. 2006). Thus, previous research has documented dramatic interspecific variation in both behavioral and population responses to drought at one wetland study site. However, it is unknown if these patterns are location-specific, or if they occur broadly across the landscape.

In this study, we investigated variation in landscape-scale effects of drought on distribution and abundance of five sympatric semi-aquatic snake species- $N$. fasciata, $N$. floridana, S. pygaea, mud snakes (Farancia abacura), and glossy crayfish snakes (Regina rigida). We systematically sampled semi-aquatic snakes at 20 wetlands before and after an intense supra-seasonal drought occurring from 2007-2012 and used an occupancy modeling framework (MacKenzie et al. 2006) to estimate pre- and post-drought species-specific detection probability $(p)$ and site occupancy $(\psi)$. We also investigated landscape and wetland characteristics (e.g., hydroperiod, distance to permanent water) that may influence shifts in abundance and distribution associated with drought. Based on previous research at Ellenton Bay (Willson et al. 2006; Winne et al. 2006), we expected that Nerodia spp., especially $N$. floridana, would be particularly sensitive to drought and decline in occupancy across the landscape, whereas occupancy of other species, especially S. pygaea, would not change during drought. Likewise, we expected declines in Nerodia spp. to be most severe in wetlands with short hydroperiods that were long distances from refuges such as the floodplain of the Savannah River. Our study represents the first landscape-scale analysis of drought effects on snake assemblages 
and highlights the importance of understanding species' responses to environmental variation that may be exacerbated by climate change.

\section{Methods}

Study Sites

We sampled 20 freshwater wetlands located on the US Department of Energy's (DOE) Savannah River Site (SRS) in 2006 (pre-drought; Fig. 1) and 2013 (post-drought) for semiaquatic snakes. From 2007-2012 the SRS experienced the most severe drought in at least the past three decades, which left most isolated wetlands dry for at least several months (Fig. 1). The SRS encompasses nearly $932 \mathrm{~km}^{2}$ within the Upper Coastal Plain of South Carolina (Aiken and Barnwell Counties), USA, and includes a variety of habitats such as bald cypress swamp, pine and hardwood forest, black water creeks, Carolina bays, and other freshwater wetlands (Davis and Janecek 1997). The Savannah River forms the western boundary of the site, with an extensive floodplain composed of semi-permanent water and lowland forest. The SRS encourages management (fire), conservation (set aside areas), and research, while limiting anthropogenic impacts, resulting in relatively undisturbed and unfragmented habitats in comparison to surrounding landscape. However, previous DOE activities resulted in radiological contamination of some areas of the site.

We selected 20 wetlands for sampling that ranged between 5 and 150 ha and represented a hydrological gradient from semi-permanent to permanent. All wetlands conformed to the following criteria: 1) open canopy, 2) surface water or precipitation fed, 3) <1 mile from access (road), 4) non-radiologically contaminated, and 5) within SRS boundaries. We included many of the wetlands within the landscape that met our criteria and we considered them to be representative of wetlands on the SRS (e.g., Thompson and Seber 1996; MacKenzie et al. 2005). Most of the wetlands in our study dried at least temporarily during the 2007-2012 drought. In our dataset, wetlands with the shortest hydroperiods were completely dry for a least eight consecutive months during this period.

\section{Field Methods}


We sampled all wetlands during May and June in 2006 (pre-drought; Durso et al. 2011)

118 and 2013 (post-drought). We captured snakes using unbaited plastic minnow traps (model 700,

119 Gator Buckets, Ladoga, IN) which are effective for capturing semi-aquatic snakes (Willson et al.

120 2008). In both years, we set one array of 60 traps each night for five consecutive nights (300

121 trap-nights) per wetland; thus one array-night (60 trap-nights) represented one sampling unit. In

122 2006, five wetlands had dried sufficiently that they could not accommodate the full array of 60

123 traps. Thus, we set traps at these five wetlands with half of the standard effort: 30 traps for 5

124 nights (150 trap-nights). We accounted for this heterogeneity in effort by incorporating a

125 sampling covariate for effort into model selection in 2006. Initial efforts to scale trapping effort

126 more closely to wetland area in 2006 introduced so many missing values into the data that

127 models often failed to converge. We placed traps 2-3 $\mathrm{m}$ apart in shallow water at the vegetated

128 periphery of each wetland, leaving $\sim 5 \mathrm{~cm}$ of trap above water to provide air for captured animals.

129 We checked traps daily, measured captured snakes (sex, snout-vent length [mm], body mass

130 [nearest $0.01 \mathrm{~g}$ on a digital balance]), and released all snakes at their capture location.

\section{Covariates}

We measured seven site covariates (Table 1) based on perceived importance and previous research (Durso et al. 2011). We measured distance to the Savannah River floodplain from the center of the wetland of interest to the nearest boundary of the floodplain, using ArcGIS (ESRI 2011). Based on a combination of historical hydrological data for some wetlands and our own observations of wetland hydrology between 1998 and 2013, we ranked the permanence of each

137 wetland as follows: 1 (never dries), 0.80 (only dries during supra-seasonal droughts), 0.60 (only dries periodically), 0.40 (typically dries annually but stays filled in wet years), 0.20 (dries 139 annually). based on the relative abundance of prey captured in minnow traps. Specifically, we allowed minnow traps to accumulate prey for the first $24 \mathrm{~h}$ after being set and counted all larval and

143 paedomorphic A.talpoideum, giant salamanders (Siren and Amphiuma), crayfish, and fishes 144 captured. We used average counts of each prey group in 2006 as a site covariate, but excluded 145 Eastern mosquitofish (Gambusia holbrooki) from fish counts due to their very small size 146 (making them unimportant as prey for most snakes) and highly variable abundances that 
swamped out general patterns of abundance of other fishes. Detection probabilities of prey groups estimated in 2006 exceeded 0.90 (Durso et al. 2011). We created a fifth prey covariate representing change in prey community during drought by subtracting pre-drought fish relative abundances (2006) from post-drought fish relative abundances (2013). We focused on fishes for this covariate because they were much more strongly affected by wetland drying than amphibians.

\section{Data Analysis}

Occupancy modeling allows estimation of the probability that a site is inhabited by a species (occupancy) while accounting for the probability that species may be missed or overlooked during surveys due to imperfect detection. We constructed single-species, singleseason occupancy models in program PRESENCE (Hines 2006) to estimate occupancy ( $\psi$ ) and detection $(p)$ of five snake species separately in pre-(2006) and post-drought (2013) years .

We used a Principal Component Analys is (PCA) in Primer (Clarke and Gorley 2006) to reduce the seven selected covariates (see Covariates) into two informative composite variables with orthogonal rotation $(\mathrm{C} 1$ and $\mathrm{C} 2)$. We combined covariates into components to reduce dimensionality, simplify model selection (2 variables instead of 7), and increase statistical power without violating common rules of thumb (number of covariates $<10-20 \%$ of sample size; Harrell 2001). We extracted the two components with the highest percent variation (C1 and C2) from a five component analysis and considered variables with correlations of $>0.30$ to be strong contributors to each component. We z-transformed all raw covariate data before conducting the PCA (Jury 1964).

We used Akaike's Information Criterion (AIC) for model selection to explore covariate effects on $\psi$ and $p$ for all candidate models. We used $\mathrm{AIC}_{\mathrm{c}}$ for all species across both seasons by specifying the effective sample size using a conservative approach based on the number of sampling units (20 wetlands; MacKenzie et al. 2006). We considered a set of sixteen models in the selection process for each species in each season (Table 2) starting with the global model, the most complex model that contains the most parameters (i.e., $\psi(\mathrm{C} 1, \mathrm{C} 2) p(\mathrm{C} 1, \mathrm{C} 2))$. From the global model, we constructed models representing each possible combination of constant (.), $\mathrm{C} 1$, and $\mathrm{C} 2$, including the null model $(\psi() p.()$.$) , for occupancy and detection (see Table 2). For$ 
2006, we included an effort covariate (E) for $p$ in all models to account for heterogeneity in sampling effort (see above). To assess model fit we used 1000 parametric bootstraps of the global model and adjusted c-hat for over or underdispersion (Akaike 1973; Burnham and Anderson 2002; MacKenzie and Bailey 2004). We reranked overdispersed models using QAIC and increased the number of model parameters by one. For underdispersed models, we inflated chat to 1 and used $\mathrm{AIC}_{\mathrm{c}}$ ranking (MacKenzie et al. 2006). Models with values $<2 \Delta \mathrm{AIC}$ were considered as supported top models.

Because PRESENCE does not present derived parameters directly in the likelihood, standard errors for all parameters must use the Delta Method to calculate the variance of backtransformed estimates to estimate $95 \%$ confidence intervals (CI). We used a simplified version by adding or subtracting ( $1.95 *$ the untransformed standard error) from the untransformed regression coefficient $(\beta)$, then back-transforming from the logit scale to get the upper or lower 95\% CI of the estimate. We inferred significant differences based on non-overlapping 95\% CIs.

In order to assess factors that might influence shifts in relative abundance of each species, we qualitatively compared capture rates of $N$. fasciata, $N$. floridana, and S. pygaea, standardized for effort (i.e., counts divided by number of trap-nights sampled), to wetland permanence and distance to the Savannah River floodplain in each year. Ideally, studies aimed at understanding variation in abundance should account for imperfect detection by using capture-mark-recapture, or similar approaches, to estimate individual capture probability. The approach used in our study (i.e., low effort across many sites) precluded the use of mark recapture, but given significant correlations between capture rates and estimated abundances found in other studies of semiaquatic snakes (King et al. 2006, Willson \& Winne, unpubl. data), we believe that these rates are meaningful indicators of abundance in our system.

\section{Results}

Aquatic trapping across 20 wetlands resulted in 242 captures of 10 species in 2006 (5250 trap-nights) and 113 captures of 10 species in 2013 (6000 trap-nights). The five species used in our analysis were Nerodia fasciata (2006 $\mathrm{n}=147$; $2013 \mathrm{n}=42$ captures), Nerodia floridana $(2006 \mathrm{n}=15 ; 2013 \mathrm{n}=5)$, Seminatrix pygaea $(2006 \mathrm{n}=37 ; 2013 \mathrm{n}=27)$, Farancia abacura $(2006 \mathrm{n}=27 ; 2013 \mathrm{n}=15)$, and Regina rigida $(2006 \mathrm{n}=5 ; 2013 \mathrm{n}=4)$. 
Principal component analysis yielded two factors that explained $62 \%$ of the cumulative variation in site covariates (Table 1): $\mathrm{C} 1,42.3 \%$ of variation (eigenvalue $=3.0$ ) and $\mathrm{C} 2,19.7 \%$ of variation (eigenvalue $=1.49)$. Principal component one $(\mathrm{C} 1)$ was strongly negatively correlated with wetland permanence, fish abundance, and giant salamander abundance, and positively correlated with A.talpoideum abundance and change in abundance of fish. Thus, wetlands with high scores for $\mathrm{C} 1$ were less permanent and had undergone a large change in fish abundance during drought, thus leading to lower abundance of fishes and giant salamanders, but higher abundance of A.talpoideum. Principal component two (C2) was strongly negatively correlated with distance to the Savannah River floodplain and positively correlated with crayfish abundance. Therefore, wetlands with higher scores for C2 were closer to the Savannah River floodplain and had higher abundance of crayfish.

Model selection revealed that for most species in both pre- and post-drought years either the null model was favored and/or multiple models were favored with low individual weight $\left(\mathrm{W}_{\mathrm{i}}\right.$; Table 2), likely due to the relatively small number of sites we were able to sample. Two species had heavily weighted top models in 2013 (post-drought). The top model for $N$. fasciata favored $\mathrm{C} 1\left(\mathrm{~W}_{\mathrm{i}}=0.65\right)$ for both occupancy and detection; indicating post-drought association with wetland permanence for this species. Conversely, the top model for $R$. rigida favored $\mathrm{C} 2\left(\mathrm{~W}_{\mathrm{i}}=\right.$ 0.66) for both occupancy and detection; indicating an association with crayfish and the Savannah River floodplain for this species.

Interspecific variation in both null model occupancy and detection occurred in both preand post-drought years (Fig. 2). Pre-drought detection estimates were relatively high, ranging from $p=0.44$ ( N. floridana) to $p=0.69$ ( N. fasciata). Pre-drought, $N$. fasciata occupied nearly every wetland sampled and had the highest estimated occupancy of any species $(\psi=0.95)$. Alternatively, the congeneric $N$. floridana occupied nearly one-third of the wetlands sampled ( $\psi$ $=0.32)$. Seminatrix pygaea was estimated to occupy approximately $40 \%(\psi=0.41)$ and $F$. abacura 50\% ( $\psi=0.52)$ of wetlands. The species with the lowest occupancy estimate predrought was $R$. rigida $(\psi=0.10)$.

Both Nerodia species suffered reductions in occupancy from pre- to post-drought seasons, whereas all other species did not change (Fig. 2a). Nerodia floridana and N. fasciata 
experienced almost identical absolute reductions in occupancy ( $N$. floridana: pre-drought $\psi=$ 0.32 ; post $\psi=0.05 ; \Delta=-0.27 ; N$. fasciata: pre-drought $\psi=0.95$; post $\psi: 0.69 ; \Delta=-0.26$ ).

However, relative to pre-drought, $N$. fasciata suffered a net reduction in occupancy of only $29 \%$, whereas $N$. floridana was nearly locally extirpated, with a net $84 \%$ reduction in occupancy. In fact, $N$. floridana was only detected in one very permanent wetland post-drought. Significant reductions in occupancy were not observed for F. abacura, S. pygaea, or R. rigida (Fig. 2a). Detection $(p)$ decreased by approximately $50 \%$ for $N$. fasciata (pre-drought: 0.69 ; post: 0.33 ), by approximately $40 \%$ for $S$. pygaea (pre-drought: 0.57 , post-drought: 0.35 ), and by $70 \%$ for $R$. rigida (pre-drought: 0.48, post-drought: 0.14) (Fig. 2b). Farancia abacura and N. floridana experienced no change in detection associated with drought.

Although our occupancy analyses lacked the power needed to detect strong covariate relationships, examination of raw capture rates of our three most common species in relation to wetland characteristics can provide information on wetland and landscape factors that may mediate the effects of drought (Fig. 3). Prior to drought, the wetlands with the highest capture rates of S. pygaea were moderately permanent and close to the Savannah River floodplain (Fig. $3 \mathrm{c}$, d). Nerodia fasciata was captured in nearly every wetland, but wetlands with the highest capture rates were moderately permanent and far from the floodplain (Fig. 3a, b). Wetlands with the highest capture rates of $N$. floridana were relatively permanent and farther from the floodplain, (Fig. 3e, f). Capture rates of all three species decreased following drought. Nerodia fasciata suffered the greatest reductions in capture rate at hydrologic extremes (i.e., very ephemeral and very permanent wetlands). Alternatively, S. pygaea was never found in extremely permanent or ephemeral wetlands pre-drought and therefore only suffered reductions in capture rate in wetlands of moderate permanence. Nerodia floridana disappeared from all but one permanent wetland after the drought, but even at this wetland, capture rates were reduced by nearly $50 \%$.

\section{Discussion}

We found interspecific variation in the effects of drought on occupancy and detection of semi-aquatic snake species. Specifically, the two Nerodia species suffered drought-induced declines in distribution and $N$. floridana was nearly extirpated from isolated wetlands across the landscape. Three species, Seminatrix pygaea, Regina rigida, and Farancia abacura, showed no 
264 change in occupancy following the drought. Pre-drought covariate effects on abundance and

265 detection were weak for all species, but snake capture rates plotted against wetland permanence

266 and distance to floodplain showed a decline in relative abundance of N. fasciata, S. pygaea, and

267 N. floridana across the study area. Wetlands with the highest abundances of $S$. pygaea were

268 moderately permanent wetlands and closer to the river floodplain, whereas $N$. fasciata declined

269 the most severely in the wetlands at both extremes of the hydrologic gradient. Our results

270 provide a unique example of how drought can influence the community composition,

271 distribution, and relative abundance of important reptilian predators in isolated wetland

272 ecosystems.

273

274

275

276

277

278

279

280

281

282

283

284

285

286

287

288

289

290

291

292

Estimated occupancy of $S$. pygaea was not affected by drought, a result that mirrors longterm population studies at Ellenton Bay. For example, relative abundance of $S$. pygaea remained virtually unchanged ( $~ 5.5$ vs. $~ 6.5$ captures per 100 trap night) at Ellenton Bay before and after a supra-seasonal drought which dried the wetland for most of 2000 and 2001 (Willson et al. 2006; Winne 2008). More detailed data for Ellenton Bay suggest that this drought resistance is due to the ability of $S$. pygaea to aestivate within the dried wetland during prolonged drought, and subsequently capitalize on high productivity once the wetland refills (Willson et al. 2006; Winne et al. 2010). However, our current study found that detection was reduced after drought, suggesting some effect of drought on S. pygaea abundance or behavior. We expect that this reduction is a result of drought-induced mortality, as indicated by a lack of large individuals of both sexes (>325 mm) after drought in 2003 (Winne et al. 2010). Although larger individuals may perish during drought, our results suggest that this mortality is of minor significance to persistence of populations, given that overall occupancy of $S$. pygaea did not change following drought. Alternatively, emigration could explain the slight reduction in detection that we observed; select studies have suggested that individuals emigrate from drying wetlands (Dodd 1992; Seigel et al. 1995). However, other studies suggest that terrestrial dispersal is physiologically demanding and unlikely for S. pygaea, especially for adults (Winne et al. 2001). Thus, our results confirm that S. pygaea is remarkably drought resistant, likely due to strategies such as aestivation that enable most individuals to survive and occupy isolated wetlands across the landscape throughout the entire drought duration. 
Similar to $S$. pygaea, $R$. rigida did not experience reductions in occupancy during

drought. We know little about the ecology and life history of $R$. rigida, which is perceived to be the rarest of our focal species (Gibbons and Dorcas 2004). Durso et al. (2011) found that $R$. rigida had higher occupancy in wetlands closer to the Savannah River floodplain containing crayfish; a relationship that stands in our post-drought analysis. One hypothesis for the resistance of $R$. rigida to drought could be found in its close taxonomic relationship with S. pygaea (McVay and Carstens 2013), which may suggest that $R$. rigida could also aestivate during drought. However, $R$. rigida has been found to exhibit terrestrial activity far from water (Steen et al. 2011), suggesting that this species may at times be more terrestrial than we usually perceive. Migration to the Savannah River floodplain, an unlikely scenario for S. pygaea due to small body size, high desiccation risk (Winne et al. 2001), and lack of preferred food (A. talpoideum) in the floodplain, seems more likely for $R$. rigida. Movement of some or many individuals out of isolated wetlands and into the floodplain during drought would also explain the observed postdrought reduction in detection.

Little is known about $F$. abacura, but its dietary preference for giant salamanders (Siren spp./Amphiuma spp.) is thought to be the primary reason for their higher abundance in more permanent wetlands, which sustain populations of these highly-aquatic prey (Durso et al. 2013). More permanent wetlands are less likely to dry completely during drought, which could explain the lack of drought effects on either occupancy or detection probability for F. abacura. Like $S$. pygaea, Farancia abacura has been reported to aestivate within or near dried wetlands (Willson et al. 2006). Although reports of aestivation are anecdotal, short distance migration from drying wetlands during drought has also been documented, although sample sizes are small (Seigel et al. 1995; Martin 1998; Willson et al. 2006; Steen et al. 2013). Additionally, the maximum size of $F$. abacura exceeds that sampled by minnow traps (Willson et al. 2008), so it is possible that large individuals could go undetected until recruitment of juvenile snakes into the population occurs. However, Winne et al. (2006) showed that post-drought survival of aestivating large female $S$. pygaea was lower than that of smaller females, so we would predict that large F. abacura, which are $>300 \%$ larger than the largest S. pygaea, are at greater risk of perishing if they remain in dried wetlands during drought. Regardless of whether F.abacura aestivate, migrate, or use a combination of the two strategies, they appear to be relatively unaffected by supra-seasonal drought. 
Unlike the above drought-resilient species, Nerodia fasciata experienced declines in both

325 occupancy and detection during the supra-seasonal drought; specifically, $\sim 30 \%$ reduction in occupancy and $\sim 50 \%$ mean reduction in detection. We interpret the reduction in detection

327 probability of $N$. fasicata to be an indication of population declines at sites where they persisted.

328 This agrees with patterns documented at Ellenton Bay, where relative abundance using minnow traps was substantially reduced from $\sim 4$ individuals per 100 trap-nights before drought (spring 1998), to zero individuals captured in minnow traps following the supra-seasonal drought in spring 2003 (Winne 2008; Winne et al. 2010). Although Seigel et al. (1995) suggested that $N$. fasciata emigrate in the direction of aquatic habitats during drying, very few N. fasciata immigrated back to the wetland after it refilled in 2003. This suggests high mortality during

334 drought or failure of snakes to make the return journey (Willson et al. 2006). It is possible that $N$. fasciata migrate to permanent habitats like the Savannah River floodplain or larger creeks and remain there permanently. Although $N$. fasciata are strongly affected by drought, they appear to be able to rapidly repopulate once water-levels return to normal (Winne 2008), a common characteristic of resilience (Bond et al. 2008).

Our study corroborates data from two historical drought events demonstrating that $N$. floridana are strongly affected by supra-seasonal drought. Prior to a supra-seasonal drought in 1985, N. floridana were fairly common within Ellenton Bay, nearly twice as abundant as $N$.

342 fasciata (Seigel et al. 1995). Subsequent supra-seasonal droughts resulted in N. floridana declining substantially, eventually to the point of becoming no longer detectable and perhaps locally extirpated (Willson et al. 2006). We found that $N$. floridana was also strongly affected by drought at the landscape scale. Pre-drought occupancy estimates were low $(\psi=0.32)$, but detection was moderate overall $(p=0.44)$, with some wetlands containing high abundances. Post-

347 drought occupancy dropped by $>80 \%$ and $N$. floridana was nearly extirpated from isolated wetlands across the landscape $(\psi=0.05)$. However, $N$. floridana retained relatively high

349 abundances within the one wetland where they persisted, as indicated by high detection 350 probability $(p=0.59)$. 
entering or exiting Ellenton Bay over nine years. Only nine $N$.floridana were captured entering or leaving during that same time period, despite relatively high numbers of resident $N$. floridana within the bay (Seigel et al. 1995). The lack of dispersing $N$. floridana, especially before and after drought periods, suggests that this species may be averse to overland dispersal. Although remaining within the wetland during drought may be beneficial for short periods (e.g., droughts can lead to concentration of prey; Canton et al. 1984), the results of our study suggest that supraseasonal droughts may outlast this species' ability to withstand unfavorable conditions. Indeed, the only wetland in our study where $N$. floridana persisted rarely, if ever, dries. It is possible that permanent bodies of water act as refugia for $N$. floridana during drought. Refugia habitats are essential to drought survival for many species (Magoulick and Kobza 2003) and may serve as source populations that facilitate population growth and recolonization of other wetlands following drought (Adams and Warren 2005; Arthington et al. 2005). We suggest that capture biases against very large individuals (Willson et al. 2008) are unlikely to be responsible for the apparent extirpation of $N$. floridana at most wetlands, because the largest individuals are the most likely to perish during times of food scarcity (Wikelski and Trillmich 1997; Winne et al. 2006).

Given that the southeastern United States is predicted to experience increases in drought frequency and intensity (Ficklin et al. 2015; Feng et al. 2016), efforts may be needed to protect sensitive wetland-associated species like $N$. floridana. Mitigating or managing drought effects is difficult, since droughts often span large spatial and temporal scales, and are unpredictable in timing and severity (Bond et al. 2008). One strategy to mitigate effects on biodiversity is the development of long-term management plans to avoid overuse of water resources (Bond et al. 2008) that affect isolated wetlands and other aquatic habitats. Alternatively, because semiaquatic snake species are diverse in their habitat preferences and responses to drought, maintaining a large number of diverse wetland types across the landscape is likely critical to maintaining diverse assemblages of snakes (Roe et al. 2004). If necessary, construction of artificial wetlands could be used to mitigate wetland loss and achieve a landscape with sufficient connectivity to sustain meta-population dynamics (Amezaga et al. 2002). Finally, providing high quality habitat corridors and avoiding barriers between wetlands would facilitate dispersal between wetlands (Roe and Georges 2007). Without intervention, changes in drought frequency 
384 385

386

387

388

389

390

391

392

393

394

395

396

397

398

399

400

401

402

403

404

405

406

407

408

409

410

411

412

413

414

415

416

and intensity may drive both local (Walls et al. 2013a) and species extinctions (Cahill et al. 2013).

\section{Acknowledgements}

This work was supported by the Department of Energy Office of Environmental Management [Award Number DE-FCO9-07SR22506]. We thank the University of Arkansas for support and funding and the Savannah River Ecology Laboratory (SREL) for providing logistical support. We thank Tracey Tuberville for graciously hosting us at SREL and Whit Gibbons, Brett DeGregorio, and Stacey Lance for logistical support and encouragement. We also thank Mark Vukovich, Joy Vukovich, Caitlin Rumrill, Becca Phillips, Brian Metts, Sean Poppy, Melissa Pilgrim, Kimberly Andrews, Gregory Skupien, Clay Noss, Mike Epperly, Wes Flynn, Cara Love, Joseph Colbert, Andrew Cronin, Matt Atkinson, David Scott, and Angela Lindell for support, and field assistance. See also acknowledgments in Durso et al. (2011).

Adams SB, Warren ML (2005) Recolonization by warmwater fishes and crayfishes after severe drought in upper Coastal Plain hill streams. Trans Am Fish Soc 134:1173-1192

Akaike H (1973) Information theory and an extension of the maximum likelihood principle. In: Petrov B, Csáki F (eds) Second International Symposium on Information Theory. Akademiai Kidao, Budapest, Tsahkadsor, Armenia, USSR, pp 267-281

Allen CD, Macalady AK, Chenchouni H, Bachelet D, McDowell N, Vennetier M, Kitzberger T, Rigling A, Breshears DD, Hogg ET (2010) A global overview of drought and heat-induced tree mortality reveals emerging climate change risks for forests. For Ecol Manag 259:660-684

Amezaga J, Santamaría L, Green AJ (2002) Biotic wetland connectivity-supporting a new approach for wetland policy. Acta Oecol 23:213-222

Arthington AH, Balcombe SR, Wilson GA, Thoms MC, Marshall J (2005) Spatial and temporal variation in fish-assemblage structure in isolated waterholes during the 2001 dry season of an arid-zone floodplain river, Cooper Creek, Australia. Mar Freshw Res 56:25-35 
Bigler C, Kulakowski D, Veblen TT (2005) Multiple disturbance interactions and drought

Bond NR, Lake P, Arthington AH (2008) The impacts of drought on freshwater ecosystems: an Australian perspective. Hydrobiologia 600:3-16

423

Burnham KP, Anderson DR (2002) Model selection and multi-model inference: a practical information-theoretic approach. Springer, New York

430

Cahill AE, Aiello-Lammens ME, Fisher-Reid MC, Hua X, Karanewsky CJ, Ryu HY, Sbeglia GC, Spagnolo F, Waldron JB, Warsi O (2013) How does climate change cause extinction? Proc R Soc Biol Sci Ser B 280:20121890

433

434

435

436

437

438

439

440

441

442

443

444

445

446

447

448

449

450

451

452

453

454

455

Canton SP, Cline LD, Short R, Ward JV (1984) The macroinvertebrates and fish of a Colorado stream during a period of fluctuating discharge. Freshw Biol 14:311-316

Clarke KR, Gorley RN (2006) PRIMER v6. United Kingdom

Dai A (2011) Drought under global warming: a review. Wiley Interdisciplinary Reviews:

Climate Change 2:45-65

Davis CE, Janecek LL (1997) DOE research Set-Aside Areas of the Savannah River Site. Savannah River Ecology Laboratory, Aiken, South Carolina,

Dodd CK (1992) Biological diversity of a temporary pond herpetofauna in north Florida sandhills. Biodivers Conserv 1:125-142

Durso AM, Willson JD, Winne CT (2011) Needles in haystacks: estimating detection probability and occupancy of rare and cryptic snakes. Biol Conserv 144:1508-1515

Durso AM, Willson JD, Winne CT (2013) Habitat influences diet overlap in aquatic snake assemblages. J Zool (Lond) 291:185-193

ESRI (2011) ArcGIS Desktop: Release 10. Environmental Systems Research Institute, Redlands, California

Feng D, Beighley E, Hughes R, Kimbro D (2016) Spatial and temporal variations in eastern U.S. hydrology: responses to global climate variability. J Am Water Resour Assoc 52:1089-1108 
459

460

461

462

463

464

465

466

467

468

469

470

471

472

473

474

475

476

477

478

479

480

481

482

483

484

485

486

487

488

489

490

491

492

493

494

Ficklin DL, Maxwell JT, Letsinger SL, Gholizadeh H (2015) A climatic deconstruction of recent drought trends in the United States. Environ Res Lett 10:044009

Gibbons JW, Dorcas ME (2004) North American Watersnakes: A Natural History. University of Oklahoma, Norman, Oklahoma, USA

Harrell F (2001) Regression Modeling Strategies: With Applications to Linear Models, Logistic Regression, and Survival Analysis. Springer, Cham, Switzerland

Harrison RD (2000) Repercussions of El Niño: drought causes extinction and the breakdown of mutualism in Borneo. Proc R Soc Biol Sci Ser B 267:911-915

Hines JE (2006) PRESENCE - Software to estimate patch occupancy and related parameters 2.4 edition. United States Geological Survey, Patuxent Wildlife Research Center, Laurel, Maryland

Hynes H (1958) The effect of drought on the fauna of a small mountain stream in Wales. Verh Internat Verein Theor Angew Limnol 8:826-833

Jury E (1964) Theory and Application of the Z-Transform Method. John Wiley and Sons, Inc., New York

King RB, Queral-Regil A, Stanford KM (2006) Population size and recovery criteria of the threatened Lake Erie watersnake: integrating multiple methods of population estimation.

Herpetol Monogr 20:83-104

Knight D (1987) Parasites, lightning, and the vegetation mosaic in wilderness landscapes. In: Turner M, Bogucki D, Bormann F, Box E, Bratton S, Dolan R, Dunn C, Forman R, Gruendling G, Guntenspergen G, Hayes T, Leitner L, Meentenmeyet V, Morrison D, Nassauer J, Odum W, Pace III W, Remillard M, Riskind D, Risser P, Sharpe D, Smith III T, Stearns F, Turner M, Westmacott R (eds) Landscape Heterogeneity and Disturbance. Springer, New York, pp 59-83

Kock R (2005) What is this infamous "wild life/livestock disease interface?" A review of current knowledge for the African continent. In: Osofsky SA (ed) Conservation and Development Interventions at the Wildlife/Livestock Interface: Implications for Wildlife, Livestock and Human Health. IUCN Species Survival Commission, Margate, United Kingdom, pp 1-13 
501

502

503

504

505

506

507

508

509

510

511

512

513

514

515

516

517

518

519

520

521

522

523

524

525

526

527

528

529

530

531

532

533

534

535

Lake P (2003) Ecological effects of perturbation by drought in flowing waters. Freshw Biol 48:1161-1172

Larimore RW, Childers WF, Heckrotte C (1959) Destruction and re-establishment of stream fish and invertebrates affected by drought. Trans Am Fish Soc 88:261-285

Lillywhite HB, Tu M-C (2011) Abundance of sea kraits correlates with precipitation. PLoS One $6: 28556$

MacKenzie DI, Bailey LL (2004) Assessing the fit of site-occupancy models. J Agric Biol Environ Stat 9:300-318

MacKenzie DI, Nichols JD, Royle JA, Pollock KH, Bailey LL, Hines JE (2006) Occupancy Estimation and Modeling: Inferring Patterns and Dynamics of Species Occurrence. Academic Press, San Diego, California, USA

MacKenzie DI, Nichols JD, Sutton N, Kawanishi K, Bailey LL (2005) Improving inferences in population studies of rare species that are detected imperfectly. Ecology 86:1101-1113

Magoulick DD, Kobza RM (2003) The role of refugia for fishes during drought: a review and synthesis. Freshw Biol 48:1186-1198

Martin CA (1998) An Ecological Profile of the Western Mud Snake (Farancia abacura reinwardtii). MS thesis, Stephen F. Austin State University, Nacogdoches, Texas, USA

McVay JD, Carstens B (2013) Testing monophyly without well-supported gene trees: Evidence from multi-locus nuclear data conflicts with existing taxonomy in the snake tribe Thamnophiini. Mol Phylogenet Evol 68:425-431

Pough FH (1980) The advantages of ectothermy for tetrapods. Am Nat 115:92-112

Pounds JA, Fogden MPL, Campbell JH (1999) Biological response to climate change on a tropical mountain. Nature 398:611-615

Rhind S, Bradley J (2002) The effect of drought on body size, growth and abundance of wild brush-tailed phascogales (Phascogale tapoatafa) in south-western Australia. Wildl Res 29:235245

Roe JH, Georges A (2007) Heterogeneous wetland complexes, buffer zones, and travel corridors: landscape management for freshwater reptiles. Biol Conserv 135:67-76 
542

550

551

552

553

554

555

556

557

558

559

560

561

562

563

564

565

566

567

568

569

570

571

572

573

574

575

576

Roe JH, Kingsbury BA, Herbert NR (2004) Comparative water snake ecology: conservation of mobile animals that use temporally dynamic resources. Biol Conserv 118:79-89

Seigel RA, Gibbons JW, Lynch TK (1995) Temporal changes in reptile populations: effects of a severe drought on aquatic snakes. Herpetologica 51:424-434

Seneviratne SI, Nicholls N, Easterling D, Goodess CM, Kanae S, Kossin J, Luo Y, Marengo J, McInnes K, Rahimi M, Reichstein M, Sorteberg A, Vera C, Zhang X (2012) Changes in climate extremes and their impacts on the natural physical environment. In: Field CB, Barros V, Stocker TF, Qin D, Dokken DJ, Ebi KL, Mastrandrea MD, Mach KJ, Plattner G-K, Allen SK, Tignor M, Midgley PM (eds) Managing the Risks of Extreme Events and Disasters to Advance Climate Change Adaptation. A Special Report of Working Groups I and II of the Intergovernmental Panel on Climate Change (IPCC). Cambridge University Press, Cambridge, UK, pp 109-230

Sperry JH, Weatherhead PJ (2008) Prey-mediated effects of drought on condition and survival of a terrestrial snake. Ecology 89:2770-2776

Steen DA, Stevenson DJ, Beane JC, Willson JD, Aresco MJ, Godwin J, Graham SP, Smith L, Howze J, Rudolph DC, Pierce J, Lee J, Gregory B, Jensen J, Stiles S, Stiles J, Nazdrowicz N, Guyer C (2013) Terrestrial movements of the Red-bellied Mudsnake (Farancia abacura) and Rainbow Snake (F. erytrogramma). Herpetol Rev 44:208-213

Steen DA, Stiles JA, Stiles SH, Guyer C, Pierce JB, Rudolph DC, Smith LL (2011) Regina rigida (Glossy Crayfish Snake). Terrestrial movements. Herpetol Rev 42:102

Thomas CD, Cameron A, Green RE, Bakkenes M, Beaumont LJ, Collingham YC, Erasmus BF, De Siqueira MF, Grainger A, Hannah L (2004) Extinction risk from climate change. Nature 427:145-148

Thompson S, Seber G (1996) Adaptive Sampling. John Wiley \& Sons, New York

Trape S (2009) Impact of climate change on the relict tropical fish fauna of Central Sahara: threat for the survival of Adrar mountains fishes, Mauritania. PLoS ONE 4:e4400

Walls SC, Barichivich WJ, Brown ME (2013b) Drought, deluge and declines: the impact of precipitation extremes on amphibians in a changing climate. Biology 2:399-418

Walls SC, Barichivich WJ, Brown ME, Scott DE, Hossack BR (2013a) Influence of drought on salamander occupancy of isolated wetlands on the southeastern coastal plain of the United States. Wetlands 33:345-354 
577

581

582

583

584

585

586

587

588

589

590

591

592

593

594

595

596

597

598

599

600

601

602

603

604

64
Wikelski M, Trillmich F (1997) Body size and sexual size dimorphism in marine iguanas fluctuate as a result of opposing natural and sexual selection: an island comparison. Evolution 51:922-936

Willson JD, Winne CT, Dorcas ME, Gibbons JW (2006) Post-drought responses of semi-aquatic snakes inhabiting an isolated wetland: insights on different strategies for persistence in a dynamic habitat. Wetlands 26:1071-1078

Willson JD, Winne CT, Keck MB (2008) Empirical tests of biased body size distributions in aquatic snake captures. Copeia 2008:401-408

Winne CT (2008) Seminatrix pygaea, a Model of Ecological Resilience in Dynamic Habitats. Ph. D. dissertation, University of Georgia, Athens, Georgia, USA

Winne CT, Ryan TJ, Leiden Y, Dorcas ME (2001) Evaporative water loss in two natricine snakes, Nerodia fasciata and Seminatrix pygaea. J Herpetol 35:129-133

Winne CT, Willson JD, Gibbons JW (2006) Income breeding allows an aquatic snake Seminatrix pygaea to reproduce normally following prolonged drought-induced aestivation. J Anim Ecol 75:1352-1360

Winne CT, Willson JD, Gibbons JW (2010) Drought survival and reproduction impose contrasting selection pressures on maximum body size and sexual size dimorphism in a snake, Seminatrix pygaea. Oecologia 162:913-922 
605

606

607

608

609

610

\begin{tabular}{lcc}
\hline & \multicolumn{2}{c}{ Component } \\
Eigenvalues & $\mathbf{C 1}$ & $\mathbf{C 2}$ \\
\cline { 2 - 3 }$\%$ Variation & 3.0 & 1.4 \\
\hline Variable & 42.3 & 19.7 \\
Permanence & \multicolumn{2}{c}{ Correlation } \\
Distance to Savannah River Floodplain & $\mathbf{- 0 . 4 4}$ & $\mathbf{C 2}$ \\
Fish relative abundance & -0.06 & -0.23 \\
Crayfish relative abundance & $\mathbf{- 0 . 5 1}$ & $\mathbf{- 0 . 6 4}$ \\
Ambystoma talpoideum relative abundance & 0.24 & 0.16 \\
Giant salamander relative abundance & $\mathbf{0 . 3 4}$ & $\mathbf{0 . 6 3}$ \\
Change in fish relative abundance & $\mathbf{- 0 . 3 1}$ & -0.28 \\
\hline
\end{tabular}

611

612

613

614

615

616

617

618

619

620

621

622 
623 Table 2 AIC model selection for five species of semi-aquatic snakes, pre- (2006) and post-

624 drought (2013). Models within < 2 AIC were considered to be supported top models and are

625 indicated in bold. $\psi=$ site occupancy, $p=$ detection probability, $E=$ effort covariate, $C 1=$ first

626 component, $C 2=$ second component, $W_{i}=$ AIC weight. * The effort covariate was included in all

627 models to account for the effect of unequal sampling effort on detection probability.

628

\begin{tabular}{llllllllllll}
\hline & \\
\hline
\end{tabular}


631 Figure 1 Water depth $(\mathrm{cm})$ readings from 1975 to 2015 at Ellenton Bay, a precipitation driven 632 isolated wetland in the Upper Coastal Plain of South Carolina. Supra-seasonal droughts are 633 indicated with arrows in 1987-1990, 2000-2003, and 2007-2012. The focus of this study is the 634 supra-seasonal drought from 2007-2012

635

636 Figure 2 Single season, null model a) occupancy ( $\psi)$ and b) detection $(p)$ probability estimates 637 for pre-drought 2006 (open bars) and post drought 2013 (grey bars) for five species of semi638 aquatic snakes across 20 wetlands in South Carolina. N. fasciata = Nerodia fasciata (banded 639 watersnake), N. floridana $=$ Nerodia floridana (Florida green watersnake), S. pygaea $=$ 640 Seminatrix pygaea (black swamp snake), F. abacura = Farancia abacura (mud snake), R. rigida $641=$ Regina rigida (glossy crayfish snake). Error bars represent 95\% confidence intervals 642

643 Figure 3 Relative abundance (effort-corrected capture rate) of snakes in relation to wetland 644 permanence and distance from the Savannah River floodplain for three species of semi-aquatic 645 snakes: (a, b) Nerodia fasciata, (c,d) Nerodia floridana, and (e,f) Seminatrix pygaea, before 646 (2006) and after (2013) supra-seasonal drought. Each point represents capture rate at one of the 64720 wetlands sampled in 2006 (open circles) and 2013 (filled circles) 


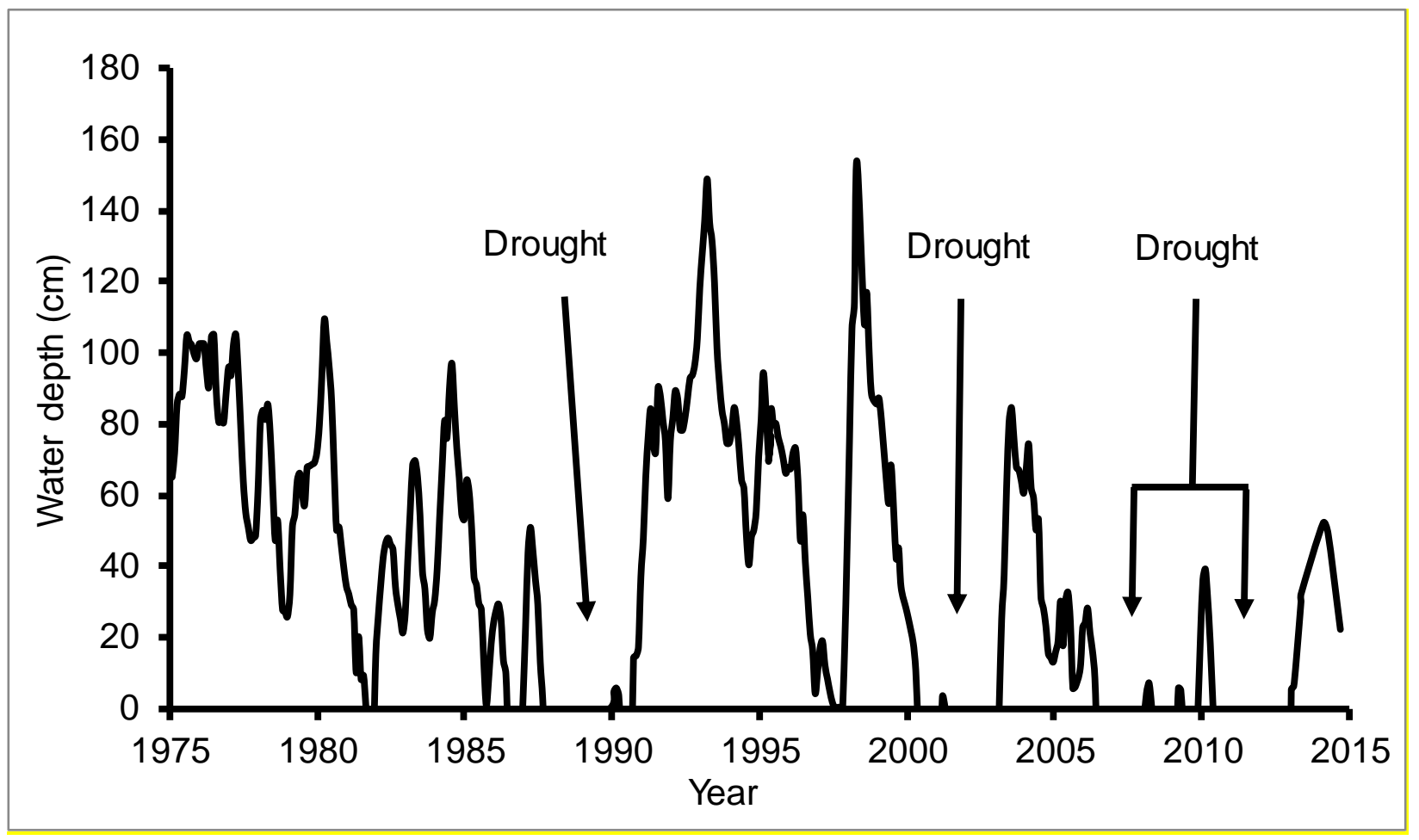

651 

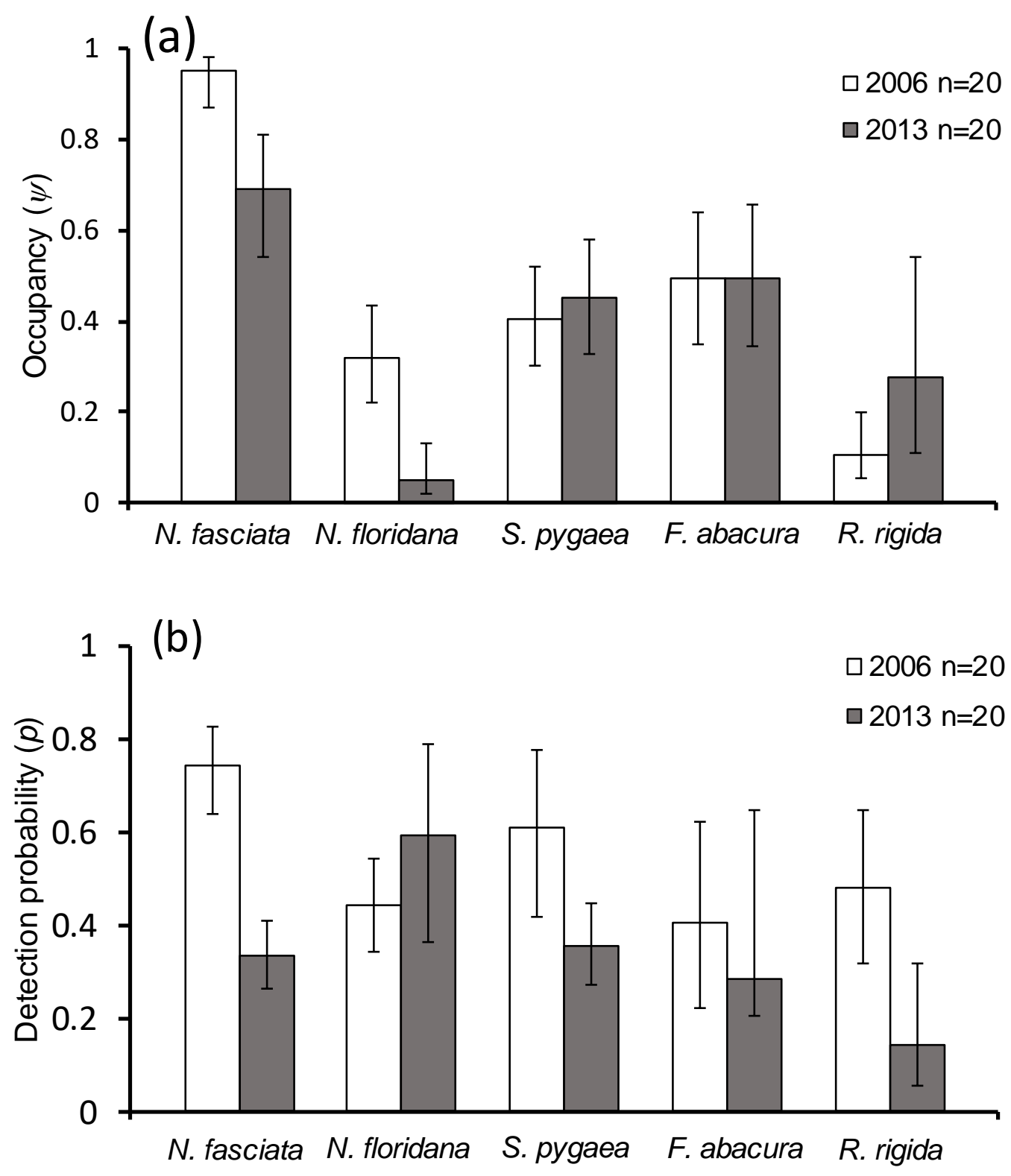

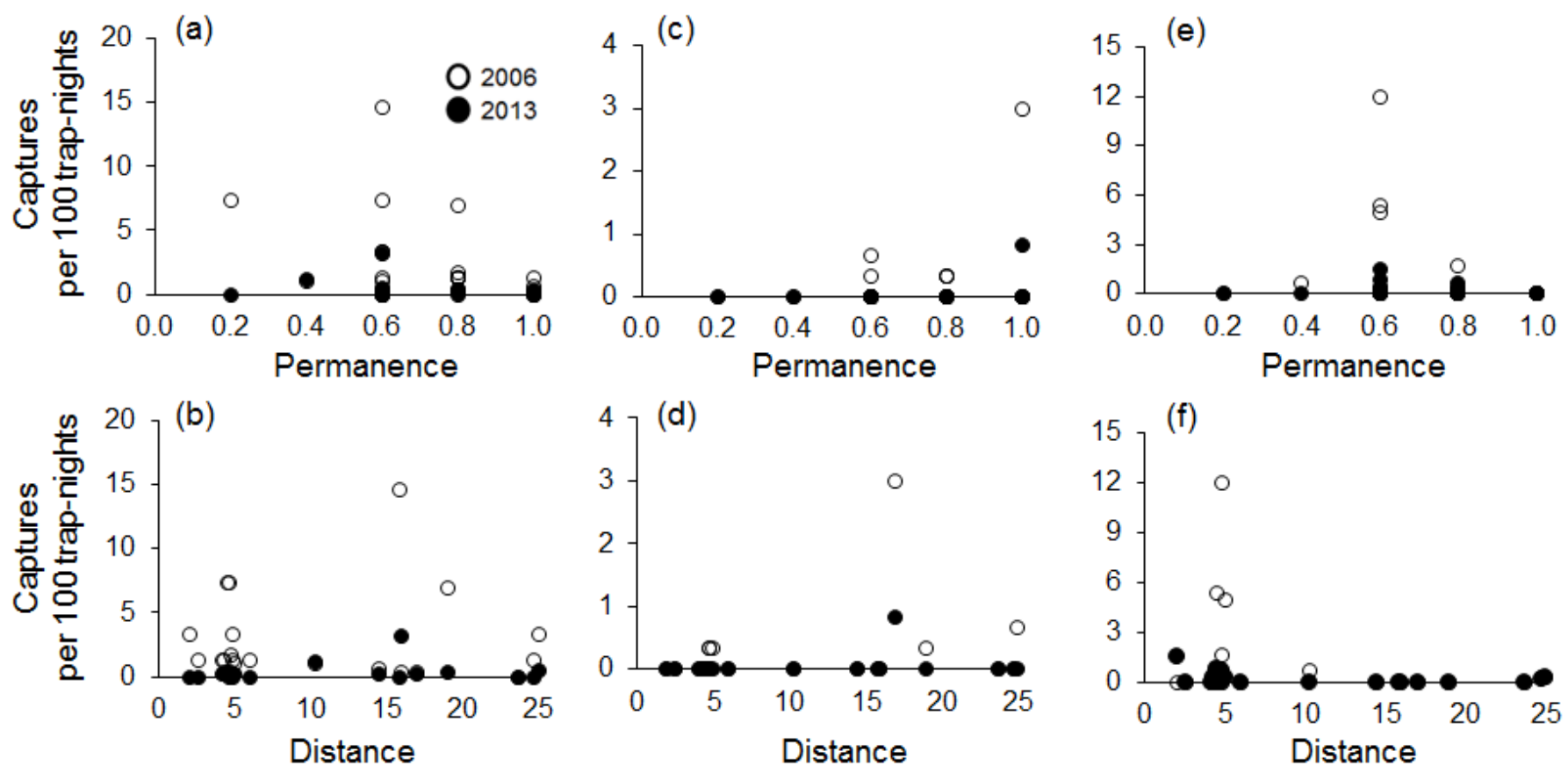

655

656 